
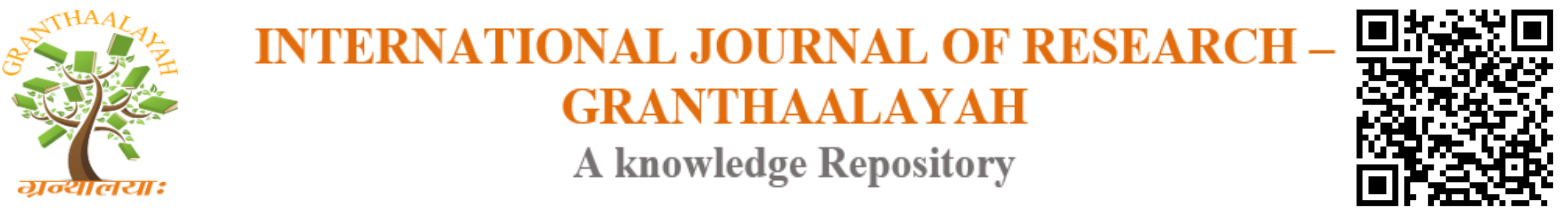

Social

\title{
THE CONTRIBUTION OF BIOETHICAL EDUCATION PROBLEMS AND PROSPECTS
}

\author{
Dr. P.K. Rejimon *1 \\ ${ }^{*}$ Independent Researcher, India
}

\begin{abstract}
Education is universally recognized as an inviolable human right in the universal declaration of human rights. It is a chance for people to satisfy their innate desire to learn, and to prepare for future, and to enable them to make contributions to the future of the society. Therefore, bioethics education means education about, for and within democracy, based on full participation of the people within social, political and cultural affairs at all levels of government, concerning them as citizens. In the present era of high tech revolution, the great task of ethically based education is to reform the human mind. The way of life of human being may change during the 21 st century. However bioethical issues impact upon all the people, the public should actively join the discussion. People have a right to reflect on their opinions in policy making; it could be argued that all have a duty to make responsible decision for the range of bioethical issues. Bioethics should be made a compulsory course with requisite attendance for the award of professional degrees. Studies have shown that making ethics an optional course in medical or professional colleges even school levels does not serve its purpose. Education and awareness are solutions to these bioethical issues. A structured curriculum is necessary for teaching of bioethics. Our decisions affect not only our individual life, but also our family, society, future generations and other living organisms. We all have a chance to study bioethics sometimes in our life.
\end{abstract}

Keywords: Bioethics; Education; UNESCO; School; Dilemma.

Cite This Article: Dr. P.K. Rejimon. (2017). "THE CONTRIBUTION OF BIOETHICAL EDUCATION PROBLEMS AND PROSPECTS." International Journal of Research - Granthaalayah, 5(7), 338-347. https://doi.org/10.29121/granthaalayah.v5.i7.2017.2139.

\section{Introduction}

Man is born with the natural faculties of love and compassion. But everywhere he is found to be a victim of negative emotions like anger, passion, hatred and jealousy. The reason is very simple because without respect for ethical values and principles, an acquisitive society cannot ensure happiness to its members. Aldus Huxley in his book 'End and means.' makes it very clear that for all purposes, the means should justify the ends and not otherwise. He asserts good things cannot be achieved by inappropriate means. This statement is more relevant to us when we try probe in to the process of bioethical oriented education as a means of human development and 
social change. We know our philosophy of life, or our beliefs and values, are an integral part of our identity that we seldom questions. Education is therefore viewed as the dynamic side of philosophy. Philosophy is the contemplation, education is action. As long as we have need and respect for values in education, it is certain that philosophy will influence both its matter and method. Some of the charges may include the absence of agricultural fields if food is grown biotechnologically. In a few years we may not use our conventional medical shops to sell bottled medicines and pads of tablets and pills. Knowing Bioethics makes us how to balance different benefits, risks and duties. Learning of bioethics empowers people to face ethical dilemmas. There is absolutely no doubt that that the study of bioethics can be enormously useful in focusing attention on problems that need to be confronted. Ethical issues are increasing day by day. So we have to consider bioethics in an efficient manner. So to avoid these problems what we need is some ethical considerations. The rapid progress of science and technology has made people how to wisely use applications. Until now; most of the decisions regarding bioethics policy have been made only by professionals, academics and ministry officials. Human beings have a right to exercise their mind and ingenuity to create alternative solutions to problems that they see to be important. As long as this creativity does not harm someone else, this right to think and then apply this thinking to innovations, is recognized on the planet as a fundamental human right. Bioethics education is necessary. Some public concern about science is based on the lack of scientific knowledge and some is based on inability to reason and balance risks and benefits and relate these between alternative technologies. These are also justified concern about the way in society is changing and what are cultural limits to technology. Education is a vital address the concern people has about ethical or social impacts of technology and to develop more informed debate. Education to be worthy of its name must encompass not only information, concepts and facts, but also attitudes and values. Bioethics is a discipline that encompasses all positive attitudes and values of life based on mutual love. This is all the more today in view of the wide spread confusion and questioning of traditional values and cultures. Our young people will have to make innumerable value laden decisions and choices and faces the many dilemmas of life in their life. It is important that they acquire the necessary knowledge and skills while they are still young. They should be alerted early in life about the problems and situations. We are all affected directly or indirectly by the decisions that we made, so the decisions should be well considered. Our decisions affect not only our own individual life, but also our family, society, future generations and other living organisms. Bioethics education is therefore essential for realizing democratic society, empowering individuals and making informed choices about the use of science and technology. Today there are powerful teaching strategies, which can be used to facilitate the process of bioethics education and development and clarification. That is bioethical values are caught and taught. Since the bioethics commission has framed the curriculum for various stages of school education and college and higher education with broader outlook towards all living beings on earth. So every one should be aware about bioethics and the issues surrounded it.

\section{International Efforts in Bioethics Education}

The above things focused on the need to establish an International education programme in bioethics. This is an education requiring expertise in many fields, but where the aim is to increase the lay understanding. Both the Universal Declaration on the Human Genome and Human Rights and the European Convention on Human Rights and Biomedicine indicate the 
need for such an education programme. Article 28 of the European convention reads, parties to this convention shall see to it that the fundamental questions raised by the developments of biology and medicine are the subject of appropriate public discussions in the light, in particular of relevant medical, social, economic, ethical and legal implications and that their particular implications is made the subject of appropriate consultation. International conventions and legal instruments are only a starting point for realizing the responsibility and solidarity of human kind in issues of bioethics.

Article 16 of the Universal Declaration of UNESCO states, States should recognize the value of promoting, at various levels as appropriate, the establishment of independent, multidisciplinary and pluralist ethics committee to assess the ethical, legal and social issues raised by research on the human genome and its applications. This underlines the importance of ethics committee as establishing fundamental point for education. In November 1995, the general conference of UNESCO adopted 28-C resolution 2.2 which invites the director general to provide assistance to those states which may request it for the creation of national bioethics committee to be concerns with the protection of universally recognized rights and freedoms. Since this specific commitment to assisting in the creation of ethics committee, UNESCO has played a role in the establishment of Bioethics Committee in places such as Lebanon and Tunisia, with preparation underway for Jordan.

Article 16 of the Universal Declaration on the Human Genome and Human Rights is entirely devoted to the importance of the ethics committee. It invites states to promote the establishment of ethics committee that are entrusted with the following tasks: to identify the ethical implications of advances in life sciences, to keep government authorities informed by providing them with detailed advice and to promote the provision of training and information to the public. All of these tasks speak to the heart of the concerns in ethics committee, these are educational tasks. The aim here is not simply to exchange information, but to develop an understanding that the cross borderlines of particular disciplines and specific disciplines.

\section{Status of Bioethics Education in Society}

Bioethics as a word or separate subject was not taught so much in India. However, more teachers had taught some social and ethical issues of the selected areas of science and technology that were asked in the survey, though still less in India. The International Bioethics Survey conducted in 1993 in ten countries, asked the question whether students should be informed about social issues associated with science and technology so that they can participate in the contemporary debates. The International Bioethics Education Survey conducted in India, found over 80\% of the biology and social studies teachers thought that bioethics education is needed. There is strong International agreement for the teaching of ethics in science and it was included in articles 20 and 21 of the Universal Declaration on the Human Genome \& Human Rights, adopted unanimously by 186 member countries of UNESCO on 11 November, 1997, as below.

20. States should take appropriate measures to promote the principles set out in the Declaration, through education and relevant means, inter alia through the conduct of research and training in interdisciplinary fields and through the promotion of education in bioethics, at all levels, in particular for those responsible for science policies. 
21. States should take appropriate measures to encourage other forms of research, training and information dissemination conducive to raising the awareness of society and all of its members of their responsibilities regarding the fundamental issues relating to the defense of human dignity which may be raised by research in biology, in genetics and in medicine, and its applications. They should also undertake to facilitate on this subject an open international discussion, ensuring the free expression of various socio-cultural, religious and philosophical opinions.

\section{Status of Bioethics Education in School Curriculum}

In school curriculum bioethics has a significant role since imparting of knowledge without considering the ethical overtones may not fulfill the most important objective of school education, namely the inculcation of values. Hundred years ago, Socrates showed that there is a link between intellectual knowledge and ethical growth. So it seems "incomplete" and perhaps, even irresponsible to teach the science of genetic engineering without exploring the broad social implications of that technology. Similarly, an explanation of the chemistry of ozone layer depletion may not be considered without inquiring into its effect on human health and all the associated social and political implications. So bioethics should be an important topic in high school curricula. The science education should not be confined to the transmission of knowledge regarding advancements in science. It is important that students should be aware of the value bases of knowledge and its relevance when they may participate in societal science decisions. The role of bioethics is significant as a way to introduce interdisciplinary thought in to non science class room instruction. Any social science class could benefit from an informed perspective on the pollution control project. So lively instructions of bioethics give both disciplines science and social science more meaning in the class room. It also honors students with genuine, frontline exposure to issues they will deal with for a life time not what is done but what ought to be done.

\section{Problems in Bioethics Education}

\subsection{Too Much Stress on Acquisition of Knowledge}

If a student takes bioethics as a collection of knowledge: philosophical terms or concepts, guidelines or recommendations, they don't have to spend much time in bioethics, because the examination will ask them only one or two questions about it. We believe bioethics needs discussion, and it should not be a one way lecture without interpersonal communication between lectures and students, or among students. But students are often accustomed to lectures without discussion. (The basic weakness of current Medical education not only at our schools, but also at many schools in this country.) Most students do not have any opportunities to exercise discussion at any stage in medical schools, and even before entering medical courses. Under the present environment, lectures in bioethics course must actively facilitate the discussion.

\subsection{The lack of Theoretical and Organizational Basis of Inter-Disciplinary Fields Extending over the Medicine, Humanities, and the Social Sciences}

The second weakness has its root in the gap between the structure of academic activity and the interdisciplinary character of bioethics. In India some medical schools are organized as a faculty 
of University, and some Medical schools are standing alone without other faculties. But even in the University which have many faculties, different departments, and many teachers specialized in diverse academic fields, medical schools are often standing alone like an island. Medical students have no contact with other students in the class room except for the first or second years. Also, quite a few medical schools, including our school, are standing in the different place from university main campus, because they need to provide medical care service at university hospitals located in the convenient city area. Students spend their first year at main campus, and come to the medical school Campus from the second year. And since then, they cannot attend course of other faculties.

\subsection{The Specific Problem for Bioethics as Epistemological Knowledge Rather than the Practical Knowledge}

Teaching bioethics requires practical knowledge by which you can relate different cases, and extract hidden ethical dilemmas. This process essentially requires the methods in applied ethics and social sciences. However the tradition of Indian philosophy is attached to epistemology and has kept its distance from applied ethics and social sciences. To address ethical dilemmas regarding informed consent, you must carefully compare the two cases using some moral concepts or principles. But this kind of practical dilemmas is actually dealt with most likely by jurists, not by philosophers in our country. We have to address every possible practical ethical dilemma in our country. In the bioethics teaching for students at clinical stage, philosophical discussion should also be started from the bed side. The encounter with real patients and health care givers will provide students real cases from which they can learn bioethics. Epistemological thinking is more important, but it should be promoted at earlier stage. But they never take these issues seriously. In the case of the scientists they believed that no significant ethical issues arise in science because they view science as objective. Ethics on the other hand involves the study of values, employs subjective methods and produces only opinion and disagreement. Hence they are not concerned themselves with ethical issues. As members of the society they will of course need to confront ethical issues.

The main problems exist in our society is that many people hold students need no formal instructions in ethics, because they believe that people learn ethics when they are very young. There is little if anything that person can learn ethics and morality by the time she enters the college. If a person is already ethical when she enters a profession she will continue to be ethical, if she is not ethical when she enters then no amount of instructions can make her become ethical. However it should not only be for professionals or academics, but it should also be understood and accepted by ordinary citizens since it greatly affecting people's lives. Thus bioethics education is necessary.

Firstly lack of some back ground knowledge may be a big barrier to deep thinking and discussion, for example structure of brain when we discuss brain death. So it's necessary to supply some relative knowledge before carrying out student's discussion. Some teaching skill should be taken in to consideration which is different from university students and medicine workers due to their own individual personalities. Secondly, since students are better at concrete thinking than abstract thinking and bioethics is still a new field to them. Some audio or video materials, pictures and stories are necessary. The primary focus of our teaching is not ethical 
knowledge but doing our best to help the students develop their awareness of moral problems and dilemmas. Most of the ethics text books are very similar to each other, which do not include the related literature or updated theories and concepts as compared with the respective international standards. Education of ethics is usually very far away from the practical problems and real life situation. We need to lobby to implement it. Bioethics should be made a compulsory course with requisite attendance for the award of professional degrees. Studies have shown that making ethics an optional course in medical or professional colleges even school levels does not serve its purpose. Another problem was that the ethical, moral and humanistic aspects of the disease are neither taught nor assessed. Consortium proposed modification of the existing under graduate curriculum based on the results of the inquiry. It was proposed to have a formal course in medical ethics.

\section{Education through Legal and Ethical Principles}

It is to be remembered that laws in every country have played highly significant role essential to the establishment, existence and progress of the nation. None as a class or profession has done more; none has much to define, to develop and to defend one liberty in the country. Ours is a democratic form of government. The different organs of the government can function only through the medium of law, which is to be protected and enforced through law courts. The welfare of the society demands the protection of the law of the land. Bioethics has an important role in law that is; in human rights most of the bioethical issues involve the questions of human dignity. Human dignity is treated as a human right by Universal declaration of Human Rights. Recent developments in technology have raised a resurgent interest in bioethics. In addition to ethical concerns of high-tech, the government also faces the pressure to strengthen the measure to ensure ethics. It covers all aspects of life including assisted reproduction, abortion; euthanasia, cloning etc.

\section{Ethical and Legal Principles}

Ethical and legal principles are the foundations of the law that guides the applications of norms relative to the object of protection. Their utility is based on three fundamental aspects. While it is difficult to agree on fixed and precise rules at the international level, it is far easier to come to a public understanding about indefinite principles that can progressively be given more concrete form. Essentially bioethics education makes an appeal to prudence addressed to policy makers who must take decisions about products or activities that could be seriously harmful to public. Some of the ethical principles are highlighted here. These laws serve as a solution to certain ethical issues in our society. Bioethics serves as guardian of the rights to health.

\section{Ethical Principles for Medical Research Involving Human subjects}

- The world medical association has developed the Declaration of Helsinki as a statement of ethical principles to provide guidance to physicians and other participants in medical research involving human subjects. Medical research involving human subjects includes research on identifiable human material or identifiable data.

- It is the duty of the physician to promote and safeguard the health of the people. The physician's knowledge and conscience are dedicated to the fulfillment of this duty. 
- The Declaration of Geneva of the world medical association binds the physician with the words the health of my patient will be my first consideration, and the International Code of Medical Ethics declares that, a physician shall act only in the patients interest when providing medical care which might have the effect of weakening the physical and mental condition of the patient.

- Medical progress is based on research which ultimately must rest in part on experimentation involving human subjects.

- In medical research on human subjects, considerations related to the well being of the human subject should take precedence over the interests of science and society.

- The primary purpose of the medical research involving human subjects is to improve diagnostic and therapeutic procedures and the understanding of the etiology and pathogenesis of disease. Even the best proven diagnostic and therapeutic methods must continuously be challenged through research for their effectiveness, efficiency, accessibility and quality.

- In current medical practice and in medical research most diagnostic and therapeutic procedures involve risks and burdens.

- Medical research is subject to ethical standards that promote respect for all human beings and protect their right and health. Some research populations are vulnerable and need special protection. The particular needs of the economically and medically disadvantaged must be recognized. Special attention is also required for those who cannot give or refuse consent under duress, for those who will not benefit personally from the research and for those for whom the research is combined.

The transplantation of human organs and assisted reproduction may be ethically justified on the ground that human life would be used for the purpose of benefiting others. Abortion and euthanasia may be justified on the ground of right to privacy and right to make informed choice. Immanuel Kant, the prominent philosopher of rationalism, felt that human beings should always be treated as ends in themselves and not as a means for another person to attain his or her ends.

\section{Significance of Bioethics Education}

\section{i. $\quad$ Public Discussion and Awareness}

In a country with high literacy rate one should expect high level of awareness about bioethics issues. Unfortunately there is low level of awareness about this. Awareness need to be created at all levels so that people can formulate a considered opinion rather than blindly following others.

\section{ii. Forming a Ethics Committee}

It is not necessary to wait for a committee or an organization to be formed in a community in order to work for bioethical issues. There is much that individual or group of individuals consulting together informally, can do. But the most effective work can be accomplished if a large committee of active, well informed citizens is gathered together and divided in to sub committees each of which can devote its energy to someone phase of the work. Antonio Spagnoto writes the ethics committees which are now public institutions deserve special attention in fact; their very existence indicates the importance of bioethics concern research as well as the welfare of people's lives and culture. Ethics committees will become increasingly a link between the worlds of scientific, research, political and civilian society. In fact in 
democratic societies every important decision will have to be the fruit of a synergy and comparison between scientists, legislators, and the consent of the population. This dialogue will not be easy, and often the legislation will be tempted to comply with public opinion even when it is against its own good, in order to obtain favors and consent. The ethics committee in then seen as the means by which ethics can put in to the questions the attitudes and the norms, and in the long run is able to modify these attitudes and norms through ethical sensitization through the development of a new dimension to ethical discourse in our society, ethics committee have been able to affect the structures of institutions ,as well as our individual dispositions, towards specific moral situations having a certain organizing regarding the decisions to be made. Institutional ethics committee creates a vehicle for education on ethical dimensions of patient care. A committee may sometimes be more easily formed in the first place for some specific activity, such as mass meeting for a prominent speaker or an open forum for the discussion of some current problem or important measure. Philosopher's day offer opportunities to organize for community action.

\section{iii. Through Seminars, Conferences and Workshops}

This should be held to encourage interaction between experts, academicians, researchers, policy makers etc.

\section{iv. Through Study Courses}

The curricula of educational institutions including Universities, Colleges and Schools should include advanced or introductory courses on bioethics. Courses on the general back ground problems of bioethical issues. Courses on special problems involved in the establishment of bioethics.

\section{v. Role of Government}

The government should know its responsibilities and should provide the necessary legal and regulatory frame work for dealing with bioethical issues and concerns. The government should institutionalize consultations among all state holders including legislators, policy makers, technical experts, public representatives, farmers and industry.

\section{vi. Role of mass media}

Mass media are sometimes referred to as the fourth power, besides legislation, administration and justice. Mass media among other televisions: report promptly new discoveries or new applications in scientific society, review on selected timely issues, make public education and enlightening in discoveries and its ethical, legal and social issues, eliminate traditional prejudices against inherited stigmata etc. These potentials are often so great .A scientist is offered opportunities by mass media in which he can introduce his own works. The media thus provide him with important chance to fulfill his responsibility to the society. Mass media themselves are informed with the progress a desirable interpretations in science. These are some useful aspects in mass media. Along with this there are undesirable aspects. In order to avoid the undesirable acts; there are laws at the national level, regulations and knows- how in each media, recommendations by expertise. In a complex society today, a scientific achievement cannot be alone and neutral. Mass media, not only having to cope with their own ethical standards, are ought to and capable to support scientists to fulfill their accountability to the public. That is through news paper, television, by air etc. Through these activities, it is possible to evaluate how 
the public responded to each issue. The merit is that we can accumulated such responses and analyzed them so that they avoid troubles and keep to be neutral.

\section{Conclusion}

The Rationale for bioethics education in this document highlights the need for capacity building in bioethics at every level of society and community in order to enable participants to express and discuss their values coherently in the bioethical discourse and to enable the public to participate in making wise decisions about their own and their children's future. The document outlines goals, challenges and recommendations and allows free and full scope for interpretation and implementation at the local level in culturally appropriate ways. It encourages educators and researchers to network in the preparation of educational resources and calls on parent institutions and governments to support the enterprise at every level. One directive, however, immediately focuses the attention, given the secular trends today. It read thus: Societies and communities will progress in a more just, equitable and sustainable direction if the cultural, ethical and spiritual value of these societies are central determinants in shaping technology and science, given that these are developing rapidly today. So a frame work is needed within which this call can be realized in our society that is; through bioethics education The aim of education must be the development of the concept of the 'bio-ethical citizen' who will be able to fully exercise his bioethical right, and be ready to take any necessary steps against the harmful and destructive endeavors destroying our society. It is also clear that bioethical problems can only be solved through the process of participatory democracy. Much bioethical activities being multidisciplinary today, there exists need for general conducts of conduct for bioethics. Their main rationale is that they benefit science in achieving its true end. A person who enters a profession is subject to certain ethical obligations according to whatever position he holds. Thus the approach of the legal system towards social and ethical values is a dominant factor in bioethics. These laws or ethical policies are the solvent of bioethics problem. Every evaluation of law involves an ethical judgment. Remember law is not a fixed body of rules, but ever changing with the changing needs of the society. Obviously bioethics deals with all issues in life and law plays a significant role in it. When dealing with bioethical issues we should get acquainted with the present ethical policies by systematic study and work directed to that object. For that legal education is necessary along with bioethics education. The main domains in which ethics is defined are governed by a particular and definitive regiment of rules called code of ethics. These rules, guidelines, canons, advisories or whatever is usually followed by members of the respective domains. Although the use of code of ethics is still limited to professions and high visibility institutions and business, there is a growing movement toward wide spread use. The wording, content and target of many codes differ greatly. Some codes are written purposely for the public, others are targeting employees, and yet others for professionals only. Bioethics deals with ethical issues arising in life by applying principles of moral philosophy. Bioethics is always based on the code of conduct. It is the application of value of ethics in our society and concerned with certain obligations towards the society. Reproduced here is certain code of ethics in bioethics.

\section{References}

[1] Darryl Macer, (1994). Perception of Risk and Benefits Invitro Fertilization, Genetic Engineering and Biotechnology, Social science and Medicine. 
[2] Darryl Macer, (2003). The Purpose of Bioethics Education: Lessons from Japan and Asia, Challenges for bioethics from Asia.

[3] Yukiko Asada \& Darryl Macer (2004). High School Bioethics Education Network in India and Japan Challenges for Bioethics from Asia.

[4] D. Macer, (1997). Bioethics Education, Awareness of Ethics and dissemination of Knowledge (Christchurch: Eubios Ethics Institute.

[5] M. Miyasaka, Ohi. G; (1995). Ethics education in Medical schools in15 Asian countries and overview Questionnaire Survey presented at East Asian Conference on Bioethics, Beijing, China.

[6] C. M. Francis, (1997). Medical Ethics in India: Ancient and Modern (I), Issues in Medical Ethics.

[7] Verma K, Nayar U, Adikoli BV, ed (1995). Inquiry driven strategies for innovation in medical education in India, All India Institute of Medical Sciences, New Delhi.

[8] D. R, J. Macer; (1994). Bioethics for the people by the people (Bangkok: Eubios Ethics Institute.

*Corresponding author.

E-mail address: pkrejimon@ gmail.com 